\title{
CAPTURE OF RELEASED APPLE MAGGOT FLIES, RHAGOLETIS POMONELLA (DIPTERA: TEPHRITIDAE), ON STICKY PANELS ${ }^{1}$
}

\author{
W. H. REISSIG \\ Department of Entomology, New York State Agricultural Experiment Station, Geneva
}

\begin{abstract}
Can. Ent. 109: 631-634 (1977)

In $1975,19.4 \%$ of 6950 marked apple maggot adults, Rhagoletis pomonella, which were released in the center of a $7 \times 7$ array of unsprayed apple trees were recaptured on Pherocon ${ }^{\circledast}$ AM traps. The distribution of the marked flies was not uniform as most of the flies were recaptured near the release point. The distribution of native flies which migrated into the test area from adjacent infested apple trees was also non-uniform.
\end{abstract}

\section{Introduction}

Various sticky traps and lures have been designed to capture apple maggot flies (AMF) Rhagoletis pomonella (Neilson 1960; Prokopy 1968; Kring 1970; Reissig 1974). These traps have been placed in heavily infested unsprayed orchards to indicate the emergence, seasonal activity, and relative abundance of AMF. Studies have been recently initiated to determine if these devices are effective enough to detect low populations of indigenous or immigrating populations of AMF in commercial apple orchards. Reissig (1975) showed that a Pherocon ${ }^{\circledast}$ AM trap with bait premixed into the adhesive was as effective in detecting flies in commercial orchards as any other trap tested, and Trottier et al. (1975) used these panels to time and schedule apple maggot control sprays in Canadian apple orchards. A knowledge of the efficiency of these panels and the migration patterns of AMF into and within commercial orchards is necessary so that effective monitoring systems can be developed for these flies.

The effectiveness of Pherocon ${ }^{\circledR}$ AM traps in capturing released AMF and the dispersal of the flies within a small block of apple trees was investigated in this study.

\section{Materials and Methods}

The test was conducted in a portion of an apple orchard near Sodus, N.Y. (Fig. 1) containing four varieties of apple trees which received normal care except that no insecticides were applied. Three sides of the test area were surrounded by woods, but the north side of the area was adjacent to an interplanting of ca. 150 Wealthy and McIntosh apple trees. These Wealthy apples were heavily infested with apple maggots the year prior to this test. One Pherocon Am trap ${ }^{2}$ (yellow cardboard panel $22 \times 30 \mathrm{~cm}$ with $1 \mathrm{~g}$ of Hycase ${ }^{\circledR}$ and ammonium acetate mixed in the adhesive) was hung $1.5-2.1 \mathrm{~m}$ above the ground on the east side of each tree in the test area. Traps were hung near the outside of the canopy radius.

Four releases of AMF 1-7 days old were made at weekly intervals, beginning 16 July and ending on 6 August. A total of 6157 laboratory-reared and 793 wild AMF were released during the test. Laboratory flies came from a colony maintained at Geneva, N.Y., for ca. 18 generations, and wild flies emerged from pupae collected the previous fall and stored at $13^{\circ} \mathrm{C}$ for ca. 30 weeks. The wild pupae were held under 16:8 LD at $44.4^{\circ} \mathrm{C}$ until they emerged. Adults of both groups received water, sucrose, and a dry diet of casein hydrolysate, salt mixture No. 2, and vitamin diet fortification mixture (Neilson and McAllan 1965), until they were released.

Plastic bags $46 \times 14 \times 5 \mathrm{~cm}$ coated inside with a thin layer of Day Glo ${ }^{\circledR}$ fluorescent pigment were used to mark flies. Ca. $0.05 \mathrm{~g}$ of pigment was shaken inside an inflated bag containing $20-25$ plastic beads $3.0 \mathrm{~mm}$ diam. to distribute it evenly on the inner

\footnotetext{
'Approved by the Director of the New York State Agricultural Experiment Station as Journal Paper No. 2281.

${ }^{2}$ Zoecon Corporation, Palo Alto, California 94304.
} 
surface. The beads were then removed and lots of ca. 200 flies immobilized by chilling were poured gently into each bag and shaken briefly until they were marked. Then they were poured into a clean plastic bag which was inflated and sealed. After they resumed activity at room temperature the bags of flies were transported to the test area in insulated ice chests and released under a McIntosh apple tree in the center of the 45 tree test block. Both groups of flies were marked with a different pigment each week so that the origin and interval after release of captured flies could be determined.

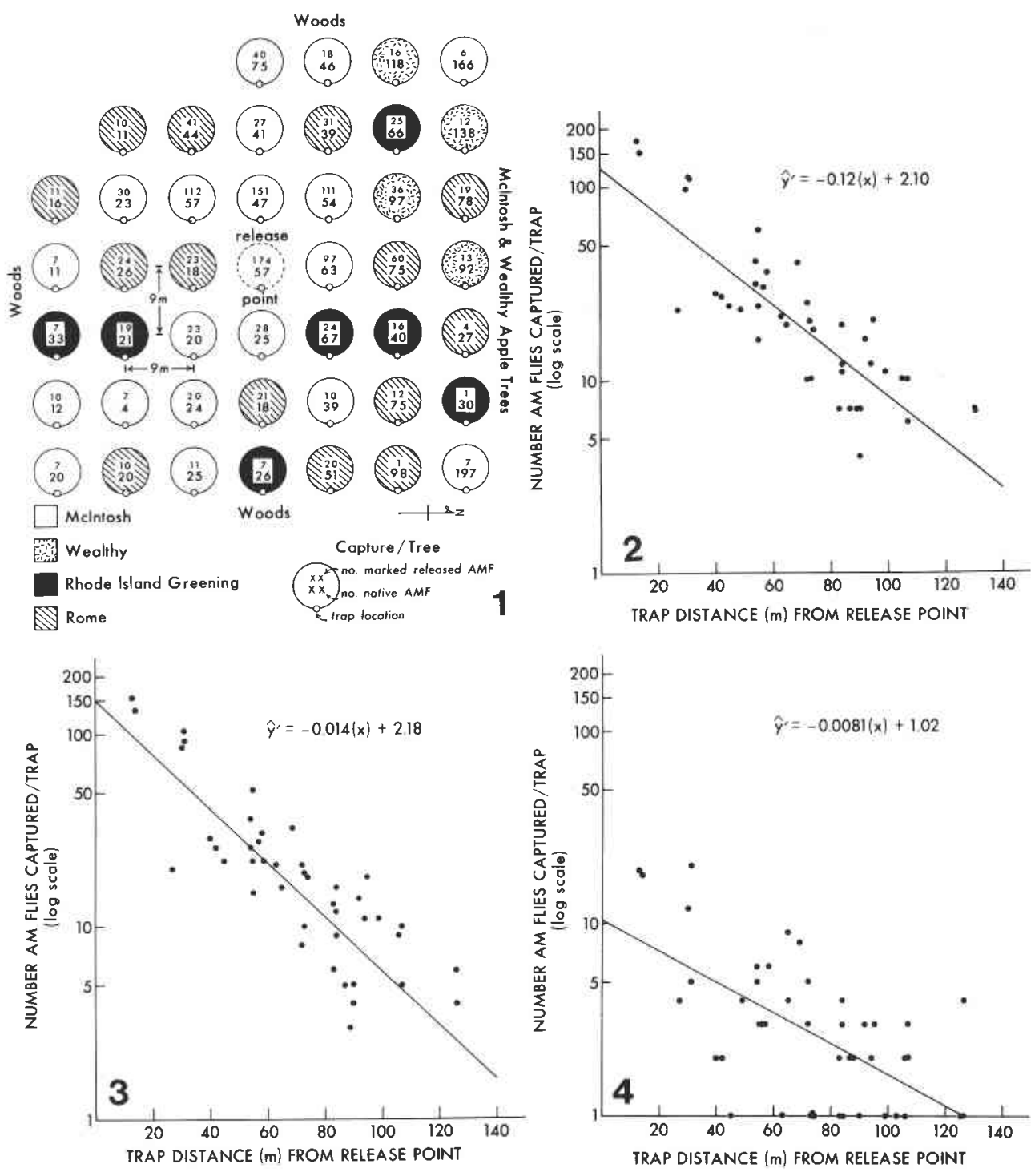

FIGs. 1-4. Seasonal capture of marked, released laboratory and wild AMF on Pherocon ${ }^{(19}$ AM traps in a portion of an unsprayed orchard. 2-4, relationship between distance from release point and (2) total number of marked released AMF captured/trap during the season, (3) number of marked released laboratory reared AMF captured/trap during the season, and (4) number of marked released wild AMF captured/trap during the season. 
Traps were removed and replaced each week beginning 1 week after the first release and continuing until 20 August, 2 weeks after the last release of flies. Each trap was then examined in a dark room in the laboratory under a lamp containing two $15 \mathrm{w}$ General Electric black lights, F15T8-BL, to identify the marked flies. The numbers of unmarked AMF indigenous to the orchard were also recorded.

The distances of traps due east or west of the release point were estimated by adding or subtracting the canopy radius of the tree containing the trap to the uniform $9 \mathrm{~m}$ spacing between tree trunks. An average canopy radius obtained by measuring several trees was used for each variety. The distances of other traps were estimated as the hypotenuse of a right triangle formed by the trap, release point and an adjacent perpendicular tree trunk.

Semilogarithmic plots were made of numbers of AMF captured on traps various distances from the release points, and equations were calculated to describe this relationship (Figs. 2-4). The percentages of wild and laboratory flies captured during the season on each trap were transformed (Arcsin) and compared with a paired $T$-test $(p<.05)$.

\section{Results and Discussion}

During the test $19.4 \%$ of the total marked flies that were released were recaptured. Considerable variation ranging from $8.9 \%$ to $25.6 \%$ occurred in capture of flies from the four separate releases. The reason for this variation is not known. Slightly more laboratory reared flies were recaptured, $19.7 \%$, than wild flies, $16.6 \%$, although this difference was not significant. Most of the AMF were captured during the first week after their release $(88.6 \%$ ), and only small numbers, $9.7,1.3$, and $0.3 \%$, were caught respectively during the second, third, and fourth weeks following their release. Most of the captured flies were females: $69.3,68.9$, and $72.7 \%$ respectively for the wild, laboratory reared, and native indigenous AMF. Since similar percentages of females were captured in the two groups of released AMF as well as the native flies, the predominance of trapped females probably represents a difference in response of the two sexes to traps rather than a reduced survival of the marked released males.

The recapture of marked AMF was much lower in this test than in a study by Buriff (1973) in which yellow sticky board traps captured $71 \%$ of marked released flies. The different traps tested in the two studies may have varied somewhat in effectiveness, but probably not enough to cause such a large difference. Buriff (1973) released flies into a small group of only eight apple trees, which may have increased the effectiveness of recapture in that study. When marked AMF were released into a larger orchard in Canada containing 66 trees in which 53 of the trees contained one sticky board trap, the recapture of flies, 20\%, was similar to that obtained in this study (Maxwell 1968).

Most of the released flies were captured on traps nearest the central release area which indicates the limited uneven dispersal of these AMF within the test area (Fig. 1). The dispersal of the wild and laboratory released flies was similar (Figs. 2-4) although larger numbers of laboratory flies were captured during the test since more were released. These results were different from those obtained by Maxwell (1968), who reported an even dispersal of marked released AMF within an orchard containing 66 trees but agreed with the results of Buriff (1973), who found that released laboratory reared flies dispersed unevenly even within the small area of an orchard containing only eight trees.

Most of the native flies that were captured throughout the test block either emerged from beneath four Wealthy apple trees heavily infested the previous year which were located in the two Northern rows of the test area or underneath the Wealthy trees adjacent to the northern border. Other varieties of apple were not large sources of native flies because they bore little fruit which was largely uninfested for 2 years prior to the 
test. The large numbers of apple maggots captured in the Wealthy trees (av. 111.2 flies/trap) compared with the lower average numbers of flies/trap $(50.3,42.5,40.4)$ captured, respectively, in the McIntosh, Rome, and Rhode Island Greening varieties suggested that many flies remained in the tree above their emergence site. A limited dispersal of native flies throughout the test area was also demonstrated by the gradually decreasing average numbers captured/trap respectively from the northern to the southern rows of the test area: 104.0, 81.2, 51.2, 41.2, 31.2, 17.5, and 18.4.

Apple maggot traps used for monitoring in commercial orchards must be located near potential sources of infestation to be effective because of the limited migration and dispersal of the flies. Even though the Pherocon ${ }^{\circledR}$ AM traps tested in this study were not as efficient as sex pheromone traps for lepidopterous orchard insect pests which have been reported to capture $82 \%$ of marked released males $1 / 4$ mile from the release point (Wong and Cleveland 1972) they may still be useful in orchard monitoring systems, if properly located.

\section{Acknowledgments}

I thank Mr. Kenneth Miller, Mr. Davis Smith, and Mr. Joseph Chayka, Jr. for technical assistance during this study and Ms. Gertrude Catlin and Ms. Rose McMillen for preparing the figures used in this manuscript.

\section{References}

Buriff, C. R. 1973. Recapture of released apple maggot flies in sticky board traps. Environ. Ent. 2: $757-758$.

Kring, J. B. 1970. Red spheres and yellow panels combined to attract apple maggot flies. J. econ. Ent. 63: 466-469.

Maxwell, C. W. 1968. Apple maggot adult dispersion in a New Brunswick apple orchard. J. econ. Ent. 61: $103-106$.

Neilson, W. T. A. 1960. Field tests of some hydrolyzed proteins as lures for the apple maggot, Rhagoletis pomonella (Walsh). Can. Ent. 92: 464-467.

Neilson, W. T. A. and J. W. McAllan. 1965. Artificial diets for the apple maggot. III. Improved, defined diets. J. econ. Ent. 58: 542-543.

Prokopy, R. J. 1968. Visual responses of apple maggot flies, Rhagoletis pomonella (Diptera: Tephritidae): Orchard studies. Entomologia exp. appl. 11: 403-422.

Reissig, W. H. 1974. Field tests of traps and lures for the apple maggot. J. econ. Ent. 67: 484-486.

1975. Evaluation of traps for apple maggot in unsprayed and commercial apple orchards. J. econ. Ent. 68: 445-448.

Trottier, R., I. Rivard, W. T. A. Neilson. 1975. Bait traps for monitoring apple maggot activity and their use for timing control sprays. J. econ. Ent. 68: $211-213$.

Wong, T. T. Y. and M. L. Cleveland. 1972. Recovery of male moths of the lesser peachtree borer in a peach orchard. Environ. Ent. 1: 344-347.

(Received 30 April 1976) 